\title{
Catgut Implantation at Baliao and Xingfu One Acupuncture Point to Treat Urinary Incontinence in Patients with Incomplete Spinal Cord Injury: Three Cases Report
}

\author{
Qingqing Li1 ${ }^{*}$, Laiming Yu², Hui Chen'1, Ruzhi Zhang³, Qiuling Liu1, \\ Maping Huang1, Dahui Zhang1, Shuqing Wu' ${ }^{1}$, Jing Liu ${ }^{1}$
}

\begin{abstract}
${ }^{1}$ Department of Neurourology Rehabilitation, Guangdong Provincial Work Injury Rehabilitation Hospital, Guangzhou, China ${ }^{2}$ Guangzhou Southern Mingdao Modified Acupuncture and Moxibustion Catgut Embedding Promotion Center, Guangzhou, China ${ }^{3}$ Subhealth Center, Guangdong Provincial Work Injury Rehabilitation Hospital, Guangzhou, China

Email: *guangzhoulqq@163.com
\end{abstract}

How to cite this paper: Li, Q.Q., Yu, L.M., Chen, H., Zhang, R.Z., Liu, Q.L., Huang, M.P., Zhang, D.H., Wu, S.Q. and Liu, J. (2019) Catgut Implantation at Baliao and Xingfu One Acupuncture Point to Treat Urinary Incontinence in Patients with Incomplete Spinal Cord Injury: Three Cases Report. Open Journal of Urology, 9, 115-118.

https://doi.org/10.4236/oju.2019.98014

Received: July 4, 2019

Accepted: August 16, 2019

Published: August 19, 2019

Copyright $\odot 2019$ by author(s) and Scientific Research Publishing Inc. This work is licensed under the Creative Commons Attribution International License (CC BY 4.0).

http://creativecommons.org/licenses/by/4.0/

\begin{abstract}
Objective: To explore the effect of catgut implantation at Baliao and Xingfu One Acupuncture point for patients with urinary incontinence secondary to spinal cord injury (SCI). Methods: Three SCI patients received catgut embedding at Baliao and Xingfu One Acupuncture point. The data of intermittent catheterization (IC) volume, intermittent catheterization frequency and the amount of using urine pad (urethral condom) were corrected. Results: Compared to the baseline data, IC volume increased and the leakage volume decreased. Conclusions: Catgut Implantation at Baliao and Xingfu One Acupuncture point is effective for patients with urinary incontinence secondary to incomplete SCI.
\end{abstract}

\section{Keywords}

Baliao and Xingfu One Acupuncture Point, Catgut Implantation, Spinal Cord Injury, Urinary Incontinence

\section{Case Report}

From 2018 to 2019, three inpatients with urinary incontinence secondary to incomplete spinal cord injury (SCI) were admitted in our department (Table 1).

All patients signed informed consent before each treatment. They received catgut embedding at bilateral Baliao and bilateral Xingfu One Acupuncture points for three times (an interval of 14 days). Four pairs of posterior sacral fo- 
ramen are called Baliao (green mark); Xingfu One Acupuncture point is flush to the fourth posterior sacral foramen and it is adjacent to the lateral margin of the sacrum (red marker) (Figure 1).

Figure 2 demonstrated catgut embedding at acupoints, disposable acupoint catgut embedding assistant package and syringe needle (Figure 2).

Patients were not allowed to bathe within 24 hours after treatment as well as no spicy and irritating foods to eat within 3 days after catgut Implantation. The amount of intermittent catheterization (IC), frequency of IC and the use of pads were reported as follows before and after treatment. Compared to the baseline data, IC volume increased and the leakage volume decreased (Table 2).

No one reported related adverse events.

Table 1. Baseline characteristics of the patients.

\begin{tabular}{ccccccc}
\hline Number & Gender & Age (y) & $\begin{array}{c}\text { Duration } \\
\text { of SCI (y) }\end{array}$ & Disease & Bladder management & Urodynamic test \\
1 & F & 37 & 2 & SCI (C4 AIS Grade D) & $\begin{array}{c}\text { Self-intermittent } \\
\text { catheterization }\end{array}$ & $\begin{array}{c}\text { Detrusor overactivity } \\
\text { during urinary storage }\end{array}$ \\
2 & F & 19 & 2 & Cauda Equina Syndrome & $\begin{array}{c}\text { Self-intermittent } \\
\text { catheterization }\end{array}$ & $\begin{array}{c}\text { Detrusor overactivity } \\
\text { during urinary storage }\end{array}$ \\
3 & M & 51 & 2 & SCI (T11 AISGrade C) & Indwelling catheter & Detrusor weakness \\
\hline
\end{tabular}

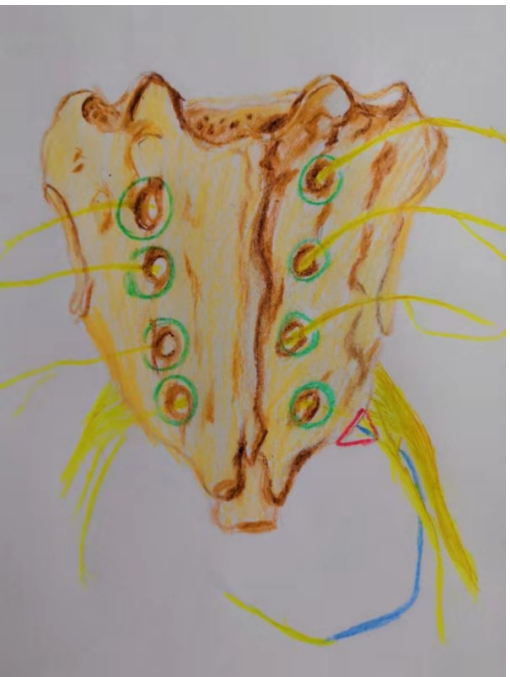

Figure 1. Anatomical sketch of Baliao and Xingfu One Acupuncture point.
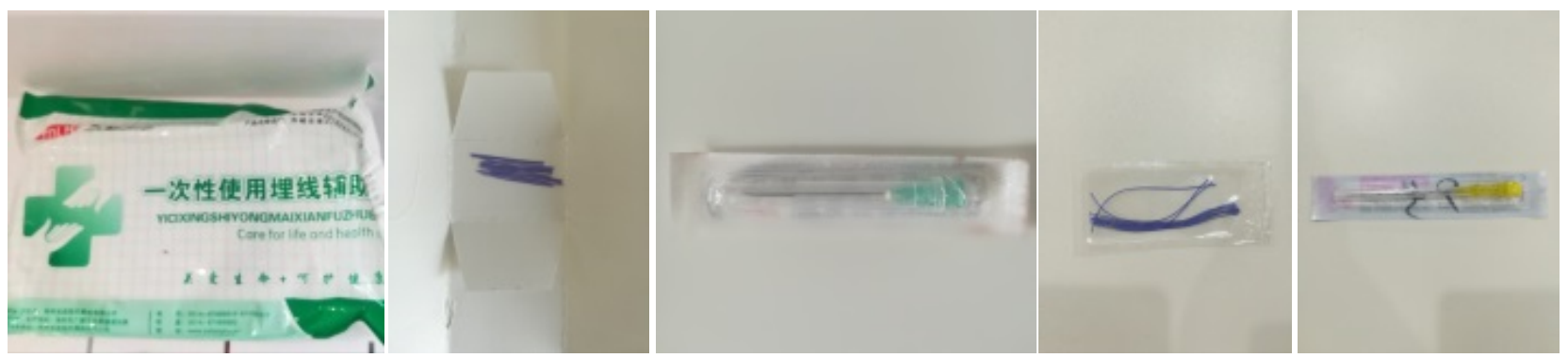

Figure 2. Catgut embedding at acupoints. 
Table 2. Urinary catheterization and urinary incontinence before and after treatment.

\begin{tabular}{ccccccc}
\hline \multirow{2}{*}{ Number } & \multicolumn{2}{c}{ IC $(\mathrm{ml})$} & \multicolumn{2}{c}{ frequency of IC (n/d) } & \multicolumn{2}{c}{ Urine pad/condom(n/d) } \\
\cline { 2 - 7 } & $\begin{array}{c}\text { Before } \\
\text { treatment }\end{array}$ & $\begin{array}{c}\text { After } \\
\text { treatment }\end{array}$ & $\begin{array}{c}\text { Before } \\
\text { treatment }\end{array}$ & $\begin{array}{c}\text { After } \\
\text { treatment }\end{array}$ & $\begin{array}{c}\text { Before } \\
\text { treatment }\end{array}$ & $\begin{array}{c}\text { After } \\
\text { treatment }\end{array}$ \\
\hline 1 & $100-260$ & $250-350$ & 3 & 5 & 3 & 3 \\
2 & $100-200$ & $200-350$ & 5 & 5 & 6 & 0 \\
3 & 0 & $400-450$ & 0 & 5 & 0 & 1 \\
\hline
\end{tabular}

\section{Discussion}

Baliao (BL 31-34), is located in four pairs of posterior sacral foramen, it is equivalent to the Sacral Jiaji Point, which belongs to the acupoints of the Bladder Meridian of Foot-Taiyang. The stimulation of the above target area can affect the excitation of pelvic nerve and pudendal nerve. Through the integration of S2-4, the bladder detrusor, the internal and external sphincter can be regulated to promote normal voiding reflex activity. Because of its unique features in the treatment of urogenital diseases, pelvic floor anorectal diseases and so on, it had been held in esteem by medical practitioners of past dynasties, especially for its obvious effect of Ciliao (BL 32). The clinical application is very extensive [1] [2] [3]. Xingfu One Acupuncture Point which is about $6 \mathrm{~cm}$ deep from the surface of the body is horizontal with the Fourth sacral posterior foramen and three transverse fingers (index, middle and ring finger) away from the sacral median ridge. It is extra nerve point, which was discovered in 2013 by Dr. Laiming Yu, an expert of Catgut Embedding and Needle Knife in China. It has a good clinical efficacy in treating urinary dysfunction, anorectal dysfunction, sexual dysfunction, gynecology and other diseases. Acupoint catgut embedding is also known as long-acting acupuncture which achieves therapeutic purposes by stimulating acupoints for a long time. This treatment is cheap, safe, simple and painless. It is easy to popularize and apply in clinic. After catgut embedding, the catheterization volume increased significantly and the leakage volume decreased. The two groups of acupoints play a mutual promotion and synergistic effect. It is a simple Chinese-style therapy of "sacral nerve regulation" and "pudendal nerve touch".

\section{Conclusion}

Catgut Implantation at Baliao and Xingfu One Acupuncture point is effective for patients with urinary incontinence secondary to SCI.

\section{Acknowledgements}

This study was supported by the funding of Administration of Traditional Chinese Medicine of Guangdong Province (grant number: 20162035).

I sincerely thank Dr. Laiming Yu, Dr. Hui Chen and Dr. Ruzhi Zhang and other medical workers for their strong support and assistance in this study. 


\section{Conflicts of Interest}

The authors declare no conflicts of interest regarding the publication of this paper.

\section{References}

[1] Yang, T., Zhi, S.L. and Yuan, S.L. (2001) 30 Cases of Neurogenic Fecal Incontinence Treated by Electro-Acupuncture at Ciliao and Huiyang Points. Xin Zhongyi Journal of New Chinese Medicine, 33, 43.

[2] Liu, X.F., Liao, Z.A., Deng, W.H., et al. (2005) Effect of Baliao Point Drug Injection and Bladder Function Training on Bladder Dysfunction in Spinal Cord Injury. Chinese Journal of Clinical Rehabilitation, 25, 142-143.

[3] Qu, M.W., Li, G.D., Hong, Z.F., et al. (2014) Clinical Observation on 30 Cases of Chronic Transport Constipation Treated by Catgut Embedding at Baliao Point. Journal of Traditional Chinese Medicine, 54, 1663-1665. 